\title{
Beatocello live in Siem Reap
}

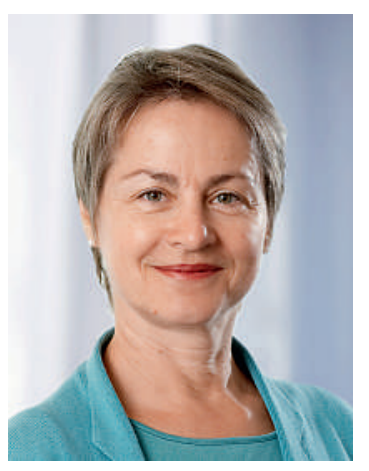

Seit Anfang Jahr reise ich durch Kambodscha und bin nun in Siem Reap angekommen, dem Eingangstor zu den Tempeln von Angkor. Seit Jahren bin ich fasziniert von diesen fremdartigen Tempeln im Urwald, mit den lotusblütenförmigen Türmen und den magischen, meterhohen Stein-Gesichtern. Der Vergangenheit als Hochkultur steht die schmerzhafte neuere Geschichte von Kambodscha gegenüber. Dieses Land ist arm, sehr arm. Nach 20 Jahren Bürgerkrieg und der Vernichtung der ganzen intellektuellen Elite muss sich das Land von Grund auf neu finden. Die Herrschaft der Roten Khmer hat einen hohen Blutzoll gefordert von den damals ca. 7 Millionen Khmer sind 1 bis 2 Millionen zu Tode gekommen, ermordet, verhungert, an Krankheiten und Erschöpfung gestorben, von Minen zerfetzt. Bis vor kurzem wurde kaum über diese schrecklichen Jahre gesprochen, jetzt haben die Prozesse gegen ehemalige Kommandeure der Roten Khmer die Schleusen endlich geöffnet.

Zurück zur Strasse nach Angkor: Sie führt an einer hoffnungsvollen Gegenwart vorbei. Ein grosses, unübersehbares Transparent weist auf das hier gelegene Kinderspital «Jajavarman VII» hin, das den Namen jenes Königs trägt, der im 12. Jahrhundert über hundert Spitäler gegründet hat. Es ist das fünfte Spital des Schweizer Kinderarztes Beat Richner (www.beat-richner.ch), der seit 20 Jahren mit beispiellosem Einsatz die kindermedizinische Versorgung Kambodschas vorantreibt. Jeden Dienstag- und Samstagabend spricht er hier über seine Arbeit, spielt auf seinem Cello - und sammelt Geld.

Im Hörsaal des Spitals wartet das Cello bereits auf der Bühne. Schliesslich kommt er, Beatocello, Arzt, Cellist und Fundraiser für seine Spitäler. Mit etwas schwerfälligen Schritten erklimmt er die Bühne, doch sobald er zu sprechen beginnt, fällt alles Schwere von ihm ab. Seine Botschaft ist einfach: Kein Kind in Kambodscha soll sterben müssen, wenn ihm nach dem Stand des heutigen medizinischen Wissens geholfen werden kann. Dafür setzt er sich mit seiner ganzen Kraft ein, stur, wenn es sein muss. Er wirbt für seine Sache, teilt Seitenhiebe aus gegen alle, die sich ihm in den Weg stellen und lässt die Fakten sprechen: In den fünf Spitälern werden $85-90 \%$ der kranken Kinder des ganzen Landes behandelt, zwei davon sind Universitätsspitäler mit entsprechendem Ausbildungsauftrag. Rund 2200 kambodschanische Ärzte und Pflegepersonen arbeiteten 2010 in den Spitälern und nur zwei Ausländer. 733000 ambulante Behandlungen wurden durchgeführt und etwa 108000 schwerkranke Kinder hospitalisiert. Vier von fünf dieser Kinder würden ohne Behandlung sterben. 14000 Geburten in der hauseigenen

\section{Kambodscha: Hochstehende kinder- medizinische Versorgung ist möglich.}

Maternité sorgen dafür, dass die Übertragungsrate von HIV unter der Geburt im Land deutlich sinkt. Zu Recht ist Beat Richner stolz darauf, dass es in seinen Spitälern keine Korruption gibt, ganz im Gegensatz zum übrigen Land. Voraussetzung dafür ist eine anständige Bezahlung aller Mitarbeitenden.

Den Zahlen folgt der Aufruf, seine Arbeit zu unterstützen: Die Finanzierung der Spitäler muss Jahr für Jahr zusammengesucht werden. Seit Januar 2005 übernimmt die kambodschanische Regierung zwar 10\% der jährlichen Betriebskosten in der Höhe von zwei Millionen Dollar, und die Schweiz steuert vier Millionen Franken bei - nachdem Micheline Calmy-Rey sich persönlich hat überzeugen lassen, dass seine Medizin hier keine Luxusmedizin ist. Doch der Grossteil der jährlich benötigten 33 Millionen Franken kommt nach wie vor von privaten Spendern. Von den «alten» Touristen möchte Richner an diesem Abend Geld, von den jungen Blut, das wegen des gerade grassierenden Dengue-Fiebers dringend benötigt wird - so kann jeder und jede etwas beisteuern.

Natürlich löst Richner mit seinem kompromisslosen Engagement für eine medizinische Versorgung nach europäischem Standard in einem armen Agrarland immer wieder Kontroversen aus. Mag sein, dass es unvernünftig ist, in einem Land wie Kambodscha, das ansonsten ein katastrophal korruptes Gesundheitswesen hat, jedes Kinderleben retten zu wollen. Aber warum eigentlich nicht? Die hochstehende kindermedizinische Versorgung in Kambodscha zeigt, dass es möglich ist. Es fehlt letztlich nicht an Geld, es fehlt der politische Wille, die weltweite, empörende Ungleichheit der Gesundheitschancen nicht länger hinnehmen zu wollen. So lange dem so ist, braucht es private Spenderinnen und Spender. Auf meiner Spendenliste ist die Konto-Nummer 80-60699-1 deshalb fest gebucht.

Dr. med. Christine Romann, Mitglied des Zentralvorstands der FMH, Verantwortliche Ressort Gesundheitsförderung und Prävention 